\title{
Reference List Errors in Manuscripts Submitted to a Journal for Review for Publication
}

\author{
Anthony J. Onwuegbuzie ${ }^{1, *}$ \& Eunjin Hwang ${ }^{1}$ \\ ${ }^{1}$ Department of Educational Leadership and Counseling, Sam Houston State University, \\ Huntsville, Texas 77341-2119, USA \\ *Corresponding author: Department of Educational Leadership and Counseling, Box 2119, \\ Sam Houston State University, Huntsville, Texas 77341-2119, USA \\ E-mail: tonyonwuegbuzie@aol.com
}

Received: August 5, 2012 Accepted: January 16, 2013 Published: April 1, 2013

doi:10.5296/ije.v5i2.2191 URL: http://dx.doi.org/10.5296/ije.v5i2.2191

\begin{abstract}
Style errors outlined in the Publication Manual of the American Psychological Association (APA) were examined among 131 manuscripts submitted to Research in the Schools, a nationally refereed journal, over a 6-year period. Specifically, a mixed research design was utilized to determine the frequency and characteristics of APA errors committed in the reference lists of these manuscripts. Findings revealed that authors committed more than 12 reference list errors per manuscript, on average $(M=12.83, S D=7.25)$. Further, a total of 466 unique reference list errors were identified, which yielded the following 14 reference list error themes: general errors, reference heading, names of authors, publication year/date, title of work, publisher information, source of journal/periodical, source of authored book, source of edited book, source of website, source of paper presentation, source of dissertation/thesis, source of newspaper article, and source of government document. Implications of these and other findings are discussed.
\end{abstract}

Keywords: reference list errors; bibliographic errors 


\section{Introduction}

Onwuegbuzie, Combs, Slate, and Frels (2010) discussed the findings of Onwuegbuzie and Combs (2009), who identified the 60 most common American Psychological Association (APA) errors among 110 sets of authors who submitted manuscripts to Research in the Schools, a nationally refereed journal, over a 6-year period. Of the 60 APA errors that were identified, the most prevalent error was the incorrect use of numbers, which occurred in $57.3 \%$ of the manuscripts, which, as concluded by Onwuegbuzie et al. (2010), represents an extremely large effect size. However, it should be noted that Combs et al. examined APA errors committed in the body of the manuscript and did not examine APA errors pertaining to reference lists.

Over the last four decades, several researchers have investigated the accuracy of reference lists in published articles across numerous fields (e.g., business, economics, medicine, social work, psychology, library information science) by comparing each reference contained in the reference list to the original work (e.g., Adhikari, \& Bhandari, 2011; Faunce \& Job, 2001; Gatten, 2010; Kristof, 1997; O'Connor \& Kristof, 2001; Spivey \& Wilks, 2004; White, 1987). Most of these researchers have reported unacceptably high rates of errors, despite the fact that, presumably, these articles had undergone a copyediting process. Thus, it is likely that manuscripts submitted to journals that have not yet been professionally copyedited in general and manuscripts that end up being rejected in particular would have even higher error rates in the reference lists. However, to date, no researcher has examined the accuracy of reference lists of manuscripts submitted to journals. Moreover, as yet, no researcher has examined the extent to which reference lists in works - whether published or unpublished - conform to the style guides of the respective journals. This was the goal of the present study. Specifically, the purpose of the study was to determine the frequency and characteristics of APA errors committed in the reference lists of manuscripts initially submitted to a nationally refereed journal, and to explore relationships between reference list errors and selected manuscript variables (e.g., number of authors, editor decision).

\section{Method}

We conducted a mixed research study wherein we examined 131 manuscripts submitted to Research in the Schools over a 6-year period. These manuscripts represented approximately $60 \%$ of all manuscripts submitted to this journal over this time frame, which made our findings generalizable to the population of manuscripts submitted to Research in the Schools. This 6-year period represented the years 2004 to 2010. We selected the year 2004 because it represented 3 years after the fifth edition of the Publication Manual was introduced-a sufficient time for users of the fourth edition to become familiar with the fifth edition of the Publication Manual of APA. Further, we selected 2010 as the end point because it represents the last year of the fifth edition and the introduction of the sixth edition.

We examined carefully the reference lists of all manuscripts and meticulously documented every reference list error committed by these 131 sets of authors. Also, we collected the 
following information: the topic of the manuscript, genre of the manuscript, number of authors per manuscript, gender of the primary author, the geographical location of the primary author's affiliation, and the Carnegie Classification (The Carnegie Foundation for the Advancement of Teaching, n.d.) that characterized each primary author's academic institution. Additionally, we documented every APA error appearing in these 131 manuscripts.

Because each manuscript contributed both qualitative and quantitative data at the same time point, the mixed research sampling design used was a concurrent design using identical samples (Collins, Onwuegbuzie, \& Jiao, 2006; Onwuegbuzie \& Collins, 2007), which has been found to be the most common sampling design in mixed research studies conducted in the social and behavioral sciences (Collins, Onwuegbuzie, \& Jiao, 2007). Further, in a concurrent design using identical samples, the qualitative and quantitative data are collected at approximately the same point in time (i.e., concurrently) such that the collection of one type of data (e.g., qualitative data) does not depend on the collection of the other type of data (e.g., quantitative data) (Onwuegbuzie \& Collins, 2007).

The qualitative and quantitative components of the study were given approximately equal weight. As such, an equal-status mixed research design was used (Johnson, Onwuegbuzie, \& Turner, 2007). Using Leech and Onwuegbuzie's (2009) typology, the research represented a fully mixed concurrent equal-status design, wherein the qualitative and quantitative data were collected at approximately the same point in time, with the quantitative and qualitative components being given approximately equal weight and mixing occurring within or across the data collection, analysis, and interpretation stages. The rationale for combining qualitative and quantitative approaches, based on Greene, Caracelli, and Graham's (1989) framework, was that of complementarity (i.e., use of quantitative and qualitative methods "to measure overlapping but also different facets of a phenomenon" [p. 258]), initiation (i.e., use of quantitative and qualitative methods "to uncover paradox and contradiction" [p. 258]), and expansion (i.e., use of quantitative and qualitative methods to "extend the scope, breadth, and range of inquiry" [p. 269]). Also, being dialectic pluralists (i.e., believing in incorporating multiple epistemological perspectives within the same inquiry; Johnson, 2011, 2012; also see Onwuegbuzie, Johnson, \& Collins, 2009), we utilized mixed analysis techniquesspecifically, a sequential mixed analysis (Onwuegbuzie \& Combs, 2010) - to investigate the prevalence and characteristics of reference list errors in the 131 manuscripts. Specifically, we used a four-stage sequential mixed analysis procedure.

\section{Results}

\subsection{Stage 1 Findings}

A classical content analysis (Berelson, 1952) revealed a total of 1,681 reference list errors across the 131 manuscripts, yielding more than 12 citation errors per manuscript, on average $(M=12.83, S D=7.25)$. The number of reference list errors per manuscript ranged from 1 to 36 , with $84.0 \%$ of manuscripts containing more than five reference list errors, $56.5 \%$ of 
manuscripts containing more than 10 reference list errors, and $15.3 \%$ of manuscripts containing more than 20 reference list errors. The classical content analysis also led to the identification of a total of 466 unique reference list errors that were committed across these 131 manuscripts. Further, this analysis revealed that the prevalence of each of these reference list errors ranged from $1(0.75 \%)$ to $102(76.7 \%)$.

Because of the number of reference list errors identified (i.e., $n=466$ ), a decision was made that an error was significantly common when it occurred a minimum of eight times. The cut-point of eight was used because it represented an endorsement rate of $6 \%$, which translated to a moderate effect size, using Cohen's (1988, 180-183) non-linear arcsine transformation criteria. Interestingly, a total of 50 reference list errors yielded endorsement rates of eight or greater. Table 1 presents these 50 most prevalent reference list errors.

Table 1: Stage 1 Findings: The 50 Most Prevalent Reference List Errors

\begin{tabular}{lc}
\multicolumn{1}{c}{ Reference List Error } & Frequency \\
\hline Serial (issue) numbers presented when the page numbers in each volume & \\
are continuous & 102 \\
Comma not presented to separate two authors & 56 \\
Superscripts inappropriately used when providing edition number & 53 \\
Space not presented between initials of each author & 49 \\
Period not presented after the author's name (when the author does not & \\
represent a person but an organization) and before the publication year & 37 \\
Website inappropriately underlined & 34 \\
Month not given for a paper presentation & 31 \\
"Publications" or "Publications Inc" inappropriately presented when & \\
listing the publisher & 30 \\
Reference list not double spaced & 28 \\
Citations not presented in alphabetical order & 27 \\
Title of journal article inappropriately capitalized & 27 \\
Comma not presented after retrieval year of Internal source & 25 \\
Volume number not italicized & 24 \\
"Inc" inappropriately presented when listing the publisher & 21 \\
Title of book inappropriately capitalized & 20 \\
"\&" not used to separate the last two authors & 17 \\
Reference heading is bolded & 18 \\
Retrieval date not provided for web-based citations & 18 \\
First letter of the second-part of the title not capitalized & 18 \\
Title of journal not italicized & 18 \\
Space not presented to separate initials of each editor of an edited book & 17 \\
\hline
\end{tabular}


Reference List Error

Frequency $^{1}$

"And" instead of " $\&$ " to separate the last two authors 14

City, state, and/or publisher not always provided 14

Title of book not always italicized 14

Period inappropriately appears after the numbers of ERIC

Page number of book chapters not presented after the title of the book 12

Space not presented between "pp " and the page number

Page number of journal articles not presented

Initials of all authors not presented

State pertaining to the publisher not abbreviated

Reference heading represented by all uppercase text

Serial number not presented when discontinuous when the page numbers in each volume are not continuous

Volume number of journal article not provided

Comma not presented to separate the last two authors of a reference

(when references have more than two authors)

Period not presented after an author's initial

Volume number of journal (periodicals) not italicized

Abbreviation (of authors) inappropriately included

Citations not presented in chronological order

Title of paper presentation not italicized

Period inappropriately presented at the end of the reference (e.g., when the reference ends with a website address)

Title of edited book not italicized

Title of journal article inappropriately italicized

Period not presented at the end of reference

Reference list does not begin on a separate page

Comma inappropriately appear between initials of some authors

State of publisher not provided

"And" instead of " $\&$ " used to separate the editors of edited books

Space inappropriately appear between six numbers of an ERIC

Space inappropriately appear between volume number and series number of a periodical 8

\footnotetext{
${ }^{1}$ Frequencies between 8 and 21 represent moderate effect sizes; frequencies greater than 22 represent large effect sizes, using Cohen's $(1988,180-3)$ non-linear arcsine transformation criteria.
} 


\subsection{Stage 2 Findings}

A constant comparison analysis of these 466 reference list errors yielded the following 14 reference list error themes: (a) General errors; (b) Reference heading, (c) Names of authors, (d) Publication year/date, (e) Title of work, (f) Publisher information, (g) Source of journal/periodical, (h) Source of authored book, (i) Source of edited book, (j) Source of website, (k) Source of paper presentation, (1) Source of dissertation/thesis, (m) Source of newspaper article, and (n) Source of government document. Once these 14 themes had been identified, the 131 manuscripts then were quantitized (Tashakkori \& Teddlie, 1998) to determine the prevalence rates of these 14 themes.

Table 2 presents descriptive statistics regarding the number of reference list errors for each of the 14 citation error themes. This table shows that reference list errors associated with the Source of journal/periodical was the most prevalent, followed by reference list errors associated with Names of authors.

Table 2: Stage 2 Findings: Prevalence Rates of Themes Emerging from Reference List Errors for Manuscripts Submitted to Research in the Schools

\begin{tabular}{lccc}
\hline Reference List Error Theme & $\begin{array}{c}\text { Total Number of } \\
\text { Unique Reference } \\
\text { List Errors } \\
\text { Contained in } \\
\text { Theme }\end{array}$ & $\begin{array}{c}\text { Number of } \\
\text { Reference } \\
\text { List Errors } \\
\text { Contained in } \\
\text { Theme }\end{array}$ & $\begin{array}{c}\text { Average incidence of } \\
\text { refence list errors per } \\
\text { manuscript (\%) }\end{array}$ \\
\hline Source of journal/periodical & 91 & 335 & \\
Names of authors & 53 & 333 & 92.4 \\
Source of edited book & 55 & 191 & 88.5 \\
Publisher information & 46 & 146 & 64.1 \\
Title of work & 35 & 108 & 61.8 \\
Source of website & 25 & 120 & 52.7 \\
General errors & 32 & 110 & 51.1 \\
Source of authored book & 31 & 94 & 48.9 \\
Source of paper presentation & 30 & 92 & 48.1 \\
Source of government & 23 & 52 & 35.9 \\
document & 19 & 38 & 22.9 \\
Publication year/date, & 7 & 39 & 22.1 \\
Reference heading & 15 & 19 & 18.3 \\
Source of dissertation/thesis & 4 & 4 & 10.7 \\
Source of newspaper article & & & 3.1 \\
\hline
\end{tabular}




\subsection{Stage 3 Findings}

A principal component analysis was used to determine the number of factors underlying the 14 reference list error themes. The Kaiser-Meyer-Olkin (KMO) measure of sampling adequacy was greater than .5 (i.e., $\mathrm{KMO}=.55$ ) and Bartlett's test of sphericity was statistically significant $\left(\mathrm{X}^{2}[91]=133.09, p=.003\right)$, which justified the principal component analysis. The eigenvalue-greater-than-one rule (i.e., K1; Kaiser, 1958) indicated that four factors (i.e., meta-themes) be retained, as did the scree test. In addition, a parallel analysis was conducted as a validity check to the K1 and scree test (Zwick \& Velicer, 1982, 1986). For the current data of 131 manuscripts and 14 variables (i.e., reference list error themes), a series of (i.e., $n=1,000$ ) random data matrices of size $131 \times 14$ was generated, and eigenvalues were computed for the correlation matrices for the original data and for each of the 1,000 random data sets. The eigenvalues derived from the actual data then were compared to the eigenvalues derived from the random data, in order to identify the number of components that accounted for more variance than did the components derived from random data. This parallel analysis also suggested retaining four factors.

This four-factor solution is presented in Table 3. Using a cutoff correlation of 0.3 , recommended by Lambert and Durand (1975) as an acceptable lower bound for pattern/structure coefficients, Table 3 reveals that the following five reference list error themes had pattern/structure coefficients with large effect sizes on the first factor: Source of website, Source of journal/periodical, Publication year/date, names of authors, and title of work; the following three reference list error themes had pattern/structure coefficients with large effect sizes on the second factor: Source of edited book, Source of authored book, and Publisher information; the following four reference list error themes had pattern/structure coefficients with large effect sizes on the third factor: Source of newspaper article, Reference heading, Source of dissertation/thesis, and Source of paper presentation; and the following two reference list error themes had pattern/structure coefficients with large effect sizes on the fourth factor: Source of government document and General errors. The first meta-theme (i.e., Factor 1) was labeled Author, Year, Journal, and Website; the second meta-theme (i.e., Factor 2) was labeled Book and Publisher, the third meta-theme (i.e., Factor 3) was labeled Heading and Non-Journal Sources, and the fourth meta-theme (i.e., Factor 4) was labeled Government and Miscellaneous Errors. 
Table 3: Stage 3 Findings: Summary of Themes and Factor Pattern/Structure Coefficients from Principal Component Analysis (Varimax): Four-Factor Solution

\begin{tabular}{|c|c|c|c|c|c|}
\hline \multicolumn{6}{|l|}{ Factor Coefficients $^{1}$} \\
\hline & & & & & Communality \\
\hline Theme & 1 & 2 & 3 & 4 & Coefficient \\
\hline Source of website & .65 & -.15 & .11 & -.40 & .62 \\
\hline Source of journal/periodical & .56 & .06 & .05 & .11 & .33 \\
\hline Publication year/date & .55 & -.02 & -.01 & .23 & .36 \\
\hline Names of authors & .48 & .24 & -.16 & -.05 & .32 \\
\hline Title of work & .40 & .20 & .19 & .25 & .30 \\
\hline Source of edited book & -.03 & .80 & -.04 & -.20 & .68 \\
\hline Source of authored book & .04 & .88 & .01 & .29 & .86 \\
\hline Publisher information & .25 & .53 & .26 & -.04 & .41 \\
\hline Source of newspaper article & -.05 & -.03 & .64 & .05 & .42 \\
\hline Reference heading & -.11 & -.02 & .64 & .13 & .44 \\
\hline Source of dissertation/thesis & .16 & .27 & .45 & -.05 & .30 \\
\hline Source of paper presentation & .22 & .11 & .42 & -.22 & .29 \\
\hline Source of government document & .16 & .04 & -.13 & .72 & .56 \\
\hline General error & .06 & -.05 & .36 & .56 & .45 \\
\hline Trace & 1.60 & 1.59 & 1.48 & 1.30 & 5.97 \\
\hline$\%$ variance explained & 11.45 & 11.35 & 10.60 & 9.31 & 42.71 \\
\hline
\end{tabular}

${ }^{1}$ Coefficients in bold represent pattern/structure coefficients with the largest effect size within each theme using a cut-off value of 0.3 recommended by Lambert and Durand (1975).

The trace (i.e., the proportion of variance explained, or eigenvalue, after rotation; Hetzel, 1996) revealed that the Author, Year, Journal, and Website meta-theme (i.e., Factor 1) explained $10.45 \%$ of the total variance; the Book and Publisher meta-theme (i.e., Factor 2) accounted for $11.35 \%$ of the variance; the Heading and Non-Journal Sources meta-theme (i.e., Factor 3) explained $10.60 \%$ of the total variance; and the Government and Miscellaneous Errors meta-theme (i.e., Factor 4) explained $9.31 \%$ of the total variance. These four meta-themes combined explained $42.70 \%$ of the total variance, yielding a large effect size (Henson, Capraro, \& Capraro, 2004; Henson \& Roberts, 2006).

The manifest effect size (i.e., actual reference list error rate per meta-theme) associated with the four meta-themes was as follows: Author, Year, Journal, and Website (97.7\%), Book and Publisher (84.0\%), Heading and Non-Journal Sources (54.2\%), and Government and Miscellaneous Errors (57.3\%). Figure 1 displays the thematic structure (i.e., relationships among the reference list error themes and the reference list error meta-themes), including the manifest effect sizes and latent effect sizes. This figure represents what Onwuegbuzie and Dickinson (2008) referred to as a crossover visual representation, which involves integrating both quantitative and qualitative findings within the same display. 

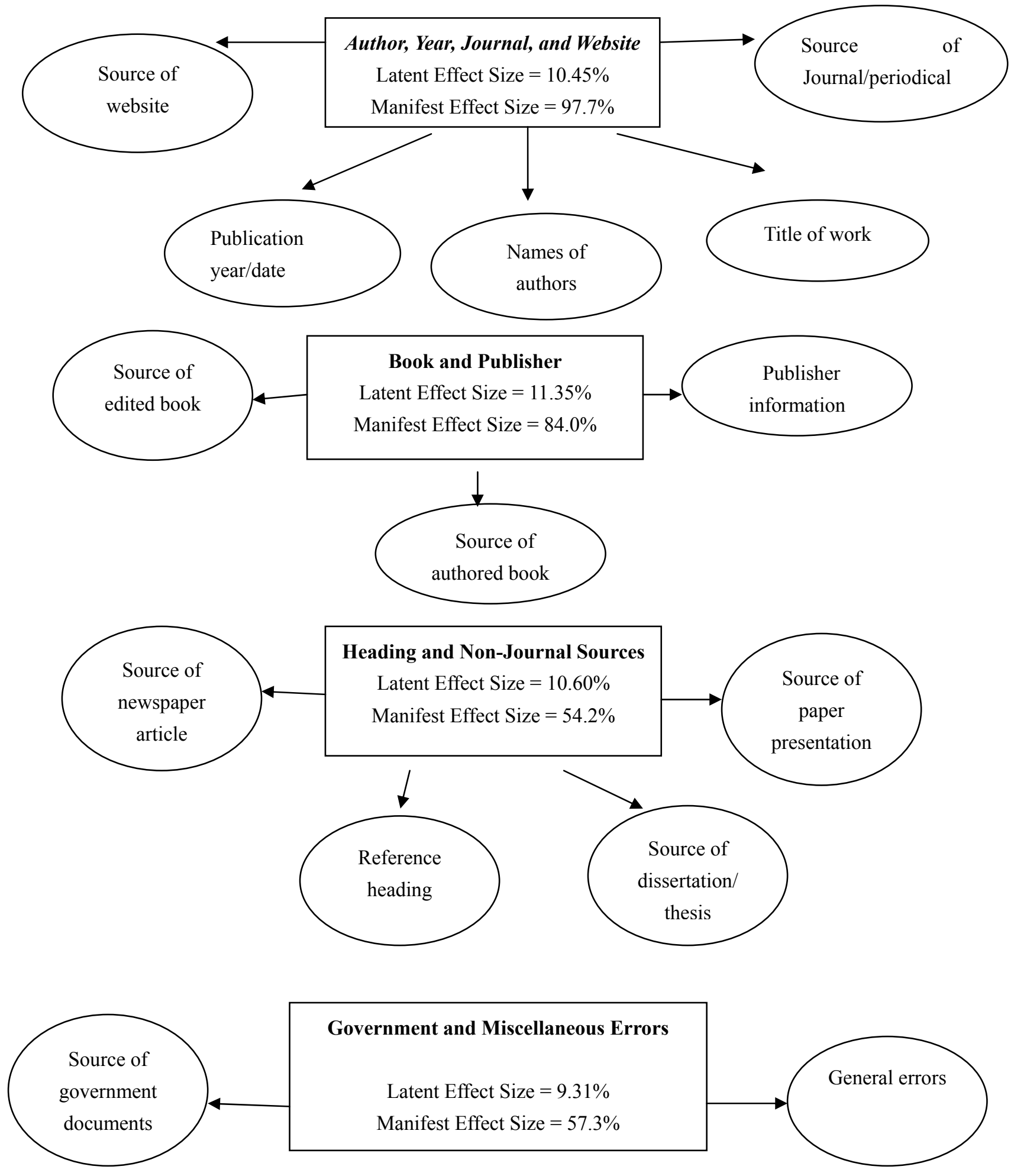

Figure 1: Stage 3 Findings: Thematic structure pertaining to reference list error themes and meta-themes 


\subsection{Stage 4 Findings}

A latent class analysis was conducted to determine the smallest number of clusters (i.e., latent classes) that accounts for all the associations among select reference list error themes. The assumption behind this latent class analysis was that a certain number of unique reference list error themes existed, and that manuscripts could be classified into a small number of distinct clusters known as latent classes based on their profiles of citation errors, such that each manuscript belonged to only one cluster. This latent class analysis represented qualitizing of the data (i.e., converting numeric data into [qualitative] narrative profiles; Tashakkori \& Teddlie, 1998). The latent class analysis was conducted on the six most common error themes because these were the themes that involved the majority of authors (i.e., $>50 \%$; cf. Table 2), namely, Names of authors, Publisher information, Source of edited book, Source of journal/periodical, Source of website, and Title of work.

The latent class analysis of the six reference list error themes revealed a two-cluster solution $\left(L^{2}=51.45, d f=50, p=.42\right.$, Bootstrap $\left.p=.11\right)$. Figure 2 displays these two distinct groups of manuscripts. Specifically, Cluster 1 (comprising $57.1 \%$ of manuscripts) was relatively high with respect to all six reference list error themes. In contrast, Cluster 2 (comprising $42.9 \%$ of manuscripts) was high on Names of authors and Source of journals/periodicals but relatively low on the remaining four reference list error themes. As can be seen from Figure 2, Publisher information (Wald $=8.69, p=.003, R^{2}=49.01 \%$ ), Source of edited book (Wald $=$ $8.58, p=.003, R^{2}=16.49 \%$ ), and Title of work (Wald $=7.10, p=.008, R^{2}=12.38 \%$ ) statistically significantly discriminated the two clusters, whereas Names of authors (Wald = $3.22, p=.07, R^{2}=8.67 \%$ ), Source of journal/periodical (Wald $=1.23, p=.027, R^{2}=1.72 \%$ ), and Source of website (Wald $=2.50, p=.11, R^{2}=4.47 \%$ ) did not. Examining the $R^{2}$ values indicates that errors associated with Publisher information had the most variance explained by the two-cluster model. 


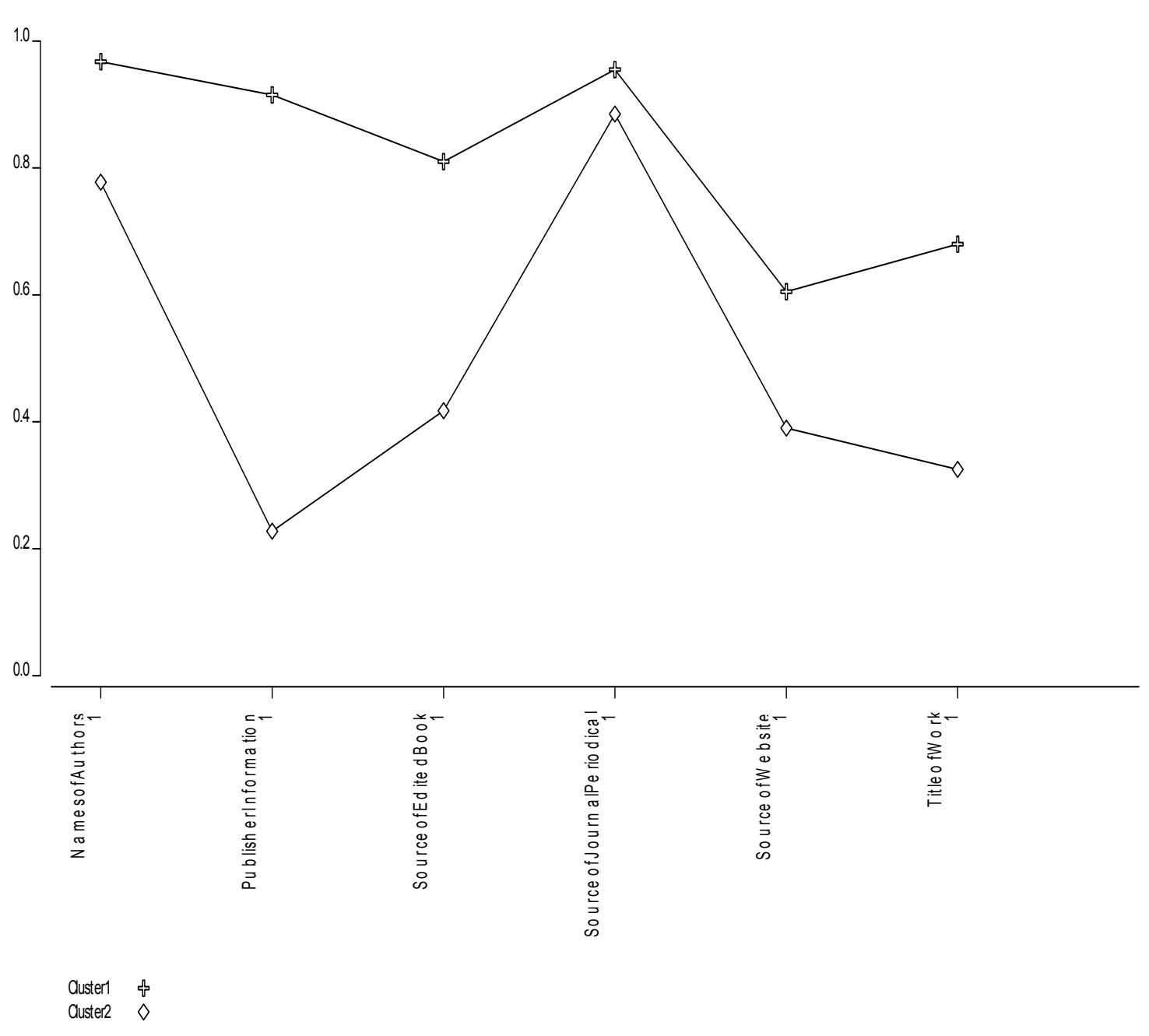

Figure 2: Stage 4 Findings: Profiles of the manuscripts with respect to the reference list error themes

\section{Discussion}

The present study is unique in at least three ways. First, it is the first formal attempt to examine the reference lists of manuscripts initially submitted to a journal. Second, it is the first attempt to investigate the extent to which reference lists in works conform to the style guides of a journal. Third, this study involved the use of mixed analysis techniques. Indubitably, reference list errors are among the most prevalent APA errors. Indeed, the prevalence of the reference list error stemming from serial (issue) numbers being presented when the page numbers in each volume are continuous $(77.9 \%)$ was 1.35 times higher than was the prevalence rate of the most common APA error involving the body of manuscripts identified by Onwuegbuzie and Combs (2009) — namely, pertaining to the incorrect use of numbers $(57.3 \%)$. Further, two of the reference list error themes, Sources of journal/periodical (92.4\%) and Names of authors (88.5\%), were significantly more prevalent than was the highest APA error theme labeled by Onwuegbuzie and Combs (2009) as 
Grammar (i.e., 65.5\%). Consequently, a unified effort is needed to end the cycle of reference list errors and to create a culture of reference lists that are minimally error free that involves college-level instructors, mentors, advisors, and thesis/dissertation committee members and chairs/supervisors, authors, journal editors, publishers, and writers of future editions of the Publication Manual.

\section{References}

Adhikari, P., \& Bhandari, S. (2011). Accuracy of references in Internet Journal of Medical Update. Internet Journal of Medical Update, 6(2), 47-49. Retrieved from http://www.akspublication.com/ijmu

Berelson, B. (1952). Content analysis in communicative research. New York, NY: Free Press.

Cohen, J. (1988). Statistical power analysis for the behavioral sciences (2nd ed.). Hillsdale, NJ: Lawrence Erlbaum.

Collins, K. M. T., Onwuegbuzie, A. J., \& Jiao, Q. G. (2006). Prevalence of mixed methods sampling designs in social science research. Evaluation and Research in Education, 19, 83-101. http://dx.doi.org/10.2167/eri421.0

Collins, K. M. T., Onwuegbuzie, A. J., \& Jiao, Q. G. (2007). A mixed method investigation of mixed methods sampling designs in social and health science research. Journal of Mixed Methods Research, 1, 267-294. http://dx.doi.org/10.1177/1558689807299526

Faunce, G. J., \& Job, R. F. S. (2001). The Accuracy of reference lists in five experimental psychology journals. American Psychologists, 56, 829-830. http://dx.doi.org/10.1037//0003-066X.56.10.829

Gatten, R. (2010). A case study in reference list accuracy. New Library World, 111(1), 16 25. http://dx.doi.org/10.1108/03074801011015658

Greene, J. C., Caracelli, V. J., \& Graham, W. F. (1989). Toward a conceptual framework for mixed-method evaluation designs. Educational Evaluation and Policy Analysis, 11, 255-274. http://dx.doi.org/10.3102/01623737011003255

Henson, R. K., Capraro, R. M., \& Capraro, M. M. (2004). Reporting practice and use of exploratory factor analysis in educational research journals: Errors and explanation. Research in the Schools, 11(2), 61-72.

Henson, R. K., \& Roberts, J. K. (2006). Use of exploratory factor analysis in published research. Educational and Psychological Measurement, 66, 393-416. http://dx.doi.org/10.1177/0013164405282485

Hetzel, R. D. (1996). A primer on factor analysis with comments on patterns of practice and reporting. In B. Thompson (Ed.), Advances in social science methodology (Vol. 4, pp. 175-206). Greenwich, CT: JAI Press. 
Johnson, R. B. (2011). Dialectical pluralism: A metaparadigm to help us hear and "combine" our valued differences. In S. J. Hesse-Biber (Chair), Addressing the Credibility of Evidence in Mixed Methods Research: Questions, Issues and Research Strategies. Plenary conducted at the meeting of Seventh International Congress of Qualitative Inquiry, University of Illinois at Urbana-Champaign.

Johnson, R. B. (2012). Dialectical pluralism and mixed research. American Behavioral Scientist, 56, 751-754. http://dx.doi.org/10.1177/0002764212442494

Johnson, R. B., Onwuegbuzie, A. J., \& Turner, L. A. (2007). Toward a definition of mixed methods research. Journal of Mixed Methods Research, 1, 112-133. http://dx.doi.org/10.1177/1558689806298224

Kaiser, H. F. (1958). The varimax criterion for analytic rotation in factor analysis. Psychometrika, 23, 187-200. http://dx.doi.org/10.1007/ BF02289233

Kristof, C. (1997). Accuracy of references in five entomology journals. American Entomology, 43, 246-251.

Lambert, Z. V., \& Durand, R. M. (1975). Some precautions in using canonical analysis. Journal of Market Research, 12, 468-475. http://dx.doi.org/10.2307/3151100

Leech, N. L., \& Onwuegbuzie, A. J. (2009). A typology of mixed methods research designs. Quality \& Quantity: International Journal of Methodology, 43, 265-275. http://dx.doi.org/10.1007/s11135-007-9105-3

O'Connor, L. G., \& Kristof, C. (2001). Verify your citations: Accuracy of reference citations in twelve business and economics journals. Journal of Business \& Finance Librarianship, 6(4), 23-40. http://dx.doi.org/10.1300/J109v06n04_03

Onwuegbuzie, A. J., \& Collins, K. M. T. (2007). A typology of mixed methods sampling designs in social science research. The Qualitative Report, 12, 281-316. Retrieved from http://www.nova.edu/ssss/QR/QR12-2/onwuegbuzie2.pdf

Onwuegbuzie, A. J., \& Combs, J. P. (2009). Writing with discipline: A call for avoiding APA style guide errors in manuscript preparation. School Leadership Review, 4, 116-149.

Onwuegbuzie, A. J., \& Combs, J. P. (2010). Emergent data analysis techniques in mixed methods research: A synthesis. In A. Tashakkori \& C. Teddlie (Eds.), Handbook of mixed methods in social and behavioral research (2nd ed., pp. 397-430). Thousand Oaks, CA: Sage.

Onwuegbuzie, A. J., Combs, J. P., Slate, J. R., \& Frels, R. K. (2010). Editorial: Evidence-based guidelines for avoiding the most common APA errors in journal article submissions. Research in the Schools. Retrieved from http://msera.org/download/RITS_16_2_APAErrors6th.pdf

Onwuegbuzie, A. J., \& Dickinson, W. B. (2008). Mixed methods analysis and information visualization: Graphical display for effective communication of research results. The 
Qualitative Report,

13 2013, Vol. 5, No. 2

http://www.nova.edu/ssss/QR/QR13-2/onwuegbuzie.pdf

Onwuegbuzie, A. J., Johnson, R. B., \& Collins, K. M. T. (2009). A call for mixed analysis: A philosophical framework for combining qualitative and quantitative. International Journal of Multiple Research Approaches, 3, 114-139. $\mathrm{http}: / / \mathrm{dx}$. doi.org/10.5172/mra.3.2.114

Spivey, C. A., \& Wilks, S. E. (2004). Reference list accuracy in social work journals. Research on Social Work Practice, 14, 281-286. http://dx.doi.org/10.1177/1049731503262131

Tashakkori, A., \& Teddlie, C. (1998). Mixed methodology: Combining qualitative and quantitative approaches. Applied Social Research Methods Series (Vol. 46). Thousand Oaks, CA: Sage.

The Carnegie Foundation for the Advancement of Teaching. (n.d.). Retrieved from http://classifications.carnegiefoundation.org/lookup_listings/institution.php

White, A. (1987). Reference list inaccuracies: A four-decade comparison. Journal of $\begin{array}{llll}\text { Counseling } \quad \& \quad \text { Development, } & 66, & 195-196 .\end{array}$ http://dx.doi.org/10.1002/j.1556-6676.1987.tb00846.x

Zwick, W. R., \& Velicer, W. F. (1982). Factors influencing four rules for determining the number of components to retain. Multivariate Behavioral Research, 17, 253-269. http://dx.doi.org/10.1207/s15327906mbr1702_5

Zwick, W. R., \& Velicer, W. F. (1986). Comparison of five rules for determining the number of components to retain. Psychological Bulletin, 99, 432-442. http://dx.doi.org/10.1037//0033-2909.99.3.432

\section{Copyright Disclaimer}

Copyright reserved by the author(s).

This article is an open-access article distributed under the terms and conditions of the Creative Commons Attribution license (http://creativecommons.org/licenses/by/3.0/). 